\title{
Tomografía de coherencia óptica
}

\author{
Optical coherence tomography
}

\author{
Juan F. Del Pozo', Carlos Fernández Pereira'
}

\section{RESUMEN}

La tomografía de coherencia óptica (OCT) es una modalidad de imagen intracoronaria, que utiliza ondas de luz cercana a la infrarroja. De esta manera se obtienen imágenes in vivo en alta resolución, cercanas a las $10 \mu \mathrm{m}$, de arterias coronarias y stents implantados. En la actualidad, múltiples estudios han demostrado la ventajas que tiene el OCT respecto del otro método de imagen intracoronario, el ultrasonido intravascular (IVUS) y la angiografía convencional (AC) para caracterizar mejor la morfología de la placa accidentada y la interacción entre el implante del stent y la pared del vaso. Esto ha abierto nuevas perspectivas con respecto al uso del OCT como herramienta en el implante de stents y el seguimiento, principalmente en angioplastias complejas donde el IVUS ya demostró disminuir la tasa de eventos respecto de la angiografía convencional a largo plazo, reduciendo la tasa de mala aposición del stent y de esta manera mejorando las tasas de reestenosis y stent trombosis.

\section{ABSTRACT}

Optical coherence tomography is an intravascular imaging modality that uses nea infrared light waves in order to reproduce in vivo images of coronary arteries and stents of resolution near to $10 \mu \mathrm{m}$. In present times, many studies had shown how this technology is better compared over conventional angiography and IVUS for assessing luminal architecture of culprit lesions and provide insights regarding sten apposition. Opening a new field of research evaluating OCT as a useful tool at the moment of $\mathrm{PCl}$, especially in complex lesion were IVUS had previously shown advantages over conventional angiography evaluating stent mal apposition and reducing clinical events such as stent thrombosis and restenosis at long term follow up.

Key words: optical coherence tomography angiography, OCT.

Palabras claves: tomografía de coherencia óptica coronaria, OCT.

Revista Argentina de Cardioangiología Intervencionista 2017;8(3):113-124

\section{INTRODUCCIÓN}

La enfermedad coronaria sigue siendo una de las principales causas de morbimortalidad tanto en países desarrollados como no desarrollados, a pesar de los grandes progresos en el campo. Se destacan cambios paradigmáticos como el adecuado control de factores de riesgo tales como la hipertensión arterial, la dislipemia y el tabaquismo o los avances en técnicas de revascularización quirúrgica o angioplastia coronaria ${ }^{1}$.

La primera reseña histórica del cateterismo cardíaco se inicia en el año 1884 cuando Claude Bernard realiza por vía retrógrada el cateterismo de los ventrículos izquierdo y derecho a través de la vena yugular y la arteria carótida en un caballo, que permitió a futuros investigadores realizar nuevos avances ${ }^{2}$. La primera evidencia que tenemos sobre el cateterismo cardíaco en un sujeto vivo fue realizada por Dr. Werner Forssman, cuando a la edad de 25 años realizó el primer cateterismo derecho con un catéter de $65 \mathrm{~cm}$ insertado en su propio brazo, logrando objetivar la ubicación en la au-

1. Sanatorio Otamendi Miroli. CABA, Argentina.

$\bowtie$ Correspondencia:Dr.Juan F. Del Pozo juanfranciscodelpozo@gmail.com

Los autores declaran no tener conflictos de intereses.

Recibido:09/06/2017|Aceptado:03/09/2017 rícula derecha por medio de una radiografía de tórax ${ }^{3}$ Los estudios continuaron y es así que, en el año 1959, el Dr. Mason Sones y colaboradores comunicaron la primera angiografía coronaria, dando inicio al método de cateterismo coronario que se utiliza en estos días ${ }^{3}$. Actualmente, la angiografía convencional (AC) es el gold standard para el diagnóstico y tratamiento de la enfermedad coronaria. Este método invasivo es eficaz para el diagnóstico y evaluación de la severidad de la enfermedad coronaria, pero con algunas limitaciones: se basa en la subjetividad del operador para evaluar el grado de lesión, con importante variabilidad inter- e intraobservador, sobre todo cuando se evalúan estenosis en el límite de severidad. Otra desventaja es que muchas veces no se puede evaluar la verdadera extensión y severidad de la enfermedad. Estudios histopatológicos demuestran que la evidencia angiográfica de estenosis no es detectada hasta que el área de la placa supera el $40-50 \%$ del área total del vaso. Esto se puede explicar por el fenómeno denominado remodelado positivo, en el que la pared externa del vaso, la membrana elástica externa, tiene la capacidad de dilatarse para acomodar el crecimiento de la placa y compensar la reducción del lumen ${ }^{4}$.

Existen nuevas técnicas invasivas que nos permiten objetivar y evaluar de mejor manera la enfermedad coronaria dentro de la Sala de Hemodinamia. Los métodos más utilizados en la actualidad son 3: la ecografía intra- 
TABLA 1. Características físicas de la OCT y del IVUS

\begin{tabular}{|c|c|c|}
\hline & OCT & IVUS \\
\hline Fuente de energía & Luz cercana a ultravioleta & Ultrasonido (12-45 MHz) \\
\hline Longitud de onda ( $\mu \mathrm{m})$ & 13 & $35-80$ \\
\hline Imágenes por segundo & $15-20$ & 30 \\
\hline Resolución ( $\mu \mathrm{m})$ & 15-20 axial, 20-40 lateral & 100-200 axial, 200-300 lateral \\
\hline Velocidad pull-back (mm/s) & $1-3$ & $0,5-1$ \\
\hline Diámetro máximo de scan (mm) & 7 & 15 \\
\hline Penetración de tejido & $1-25$ & 10 \\
\hline
\end{tabular}

OCT: tomografía de coherencia óptica. IVUS: ultrasonido intravascular. Tabla modificada de referencia 6.

coronaria o IVUS (intravascular ultrasound) con VH (virtual histology), la tomografía de coherencia óptica u OCT (optical coherence tomography) y por último la reserva fraccional de flujo o FFR (fractional flow reserve). La tomografía de coherencia óptica es una herramienta invasiva basada en el uso de luz cercana a la infrarroja para el estudio del tejido en los vasos coronarios. Desde sus inicios en 1990, esta se ha ido perfeccionando y su uso es cada vez más común.

El objetivo es revisar la bibliografía disponible sobre la tomografía de coherencia óptica y evaluar de qué manera esta metodología puede ser una herramienta para la estrategia tanto de prevención como de tratamiento de la enfermedad coronaria.

\section{MATERIAL Y MÉTODOS}

Se realizó una búsqueda exhaustiva de información las distintas fuentes bibliográficas disponibles publicadas entre los años 1993 y 2017.

Se consultaron estudios aleatorizados, metaanálisis, artículos originales, revisiones y consensos médicos de las distintas sociedades internacionales. Estos textos fueron encontrados a través de los portales de internet de PubMed (base de datos de la biblioteca nacional de Estados Unidos) y en las principales revistas internacionales y nacionales de cardiología. Se consideraron las guías y/o consensos de las sociedades cardiológicas Europea, Americanas y la del CACI (Colegio Argentino de Cardiología Intervencionista).

Se utilizaron los siguientes términos aislados o en combinación, para limitar dicha búsqueda: optical coherence tomography (OCT), vulnerable plaque, stent malapposition, enfermedad coronaria, placa vulnerable, tomografia de coherencia optica.

Una vez obtenido todo el material bibliográfico, este fue clasificado por método diagnóstico según fecha y relevancia científica. Se excluyeron publicaciones en idiomas distintos del español o inglés así como aquellas realizadas de forma experimental en animales.

\section{DESARROLLO}

\subsection{OCT, principios básicos}

La OCT utiliza ondas de luz de forma análoga como el IVUS utiliza ultrasonido para producir imágenes de la arteria. Tales ondas de luz son casi infrarrojas, en torno a los $1.300 \mathrm{~nm}$. La luz tiene una velocidad mucho más alta que la del sonido y, por esta razón, la OCT puede especificar la morfología del vaso con una resolución 10 veces mayor que la obtenida por IVUS. Aquella tiene una resolución axial de 10 micras comparadas con las 100-150 micras obtenidas por IVUS. La OCT es muy sensible al momento de evaluar la superficie luminal del vaso, pero al usar ondas de luz tiene mucho menos capacidad de evaluar las capas más profundas del vaso: únicamente puede evaluar hasta 1,5-2 mm de profundidad comparados con los 4-8 mm observados en el IVUS ${ }^{56}$ (Tabla 1).

Otro aspecto importante es que al utilizar las propiedades ópticas que tienen los distintos tejidos para reflejar la luz, la sangre con los componentes hemáticos suele generar una alteración importante de la imagen y es necesario desplazarla utilizando sustancia de contraste para obtener un estudio adecuado. Esta fue, sin duda, una de las primeras limitaciones del método.

La primera generación de OCT utilizó una tecnología denominada dominio-tiempo (OCT-TD), la velocidad de pullback estaba limitada a $1 \mathrm{~mm} / \mathrm{s}$. Ello hacía necesario dejar el vaso sin sangre durante un período prolongado de tiempo, por lo que era necesario realizar la técnica oclusiva con empleo de un balón de baja presión a nivel proximal y se inyectaba suero de contraste a nivel distal. Esto limitaba a visualizar segmentos cortos para evitar la isquemia prolongada. El gran cambio surgió con los sistemas de segunda generación, llamados FD-OCT (frequency domain $O C T$ ), sistema disponible comercialmente (C7XR system, SJM/LightLab Inc.), en el que la velocidad del pullback se aumentó hasta $20 \mathrm{~mm} / \mathrm{s}$. De esta forma, con una inyección corta de contraste de 2-3 segundos, similar a la que realizamos para una angiografía coronaria, se pueden adquirir imágenes de un segmento largo de la arteria de forma efectiva y segura?

En el año 2007, el grupo Italiano de Prati y colaboradores publicaron un estudio de 64 pacientes utilizando la técnica no oclusiva y demostraron que el método es muy efectivo y tiene una alta tasa de reproducibilidad inter-e intraobservador para evaluar el área luminal $(\mathrm{R}: 0,96 ; \mathrm{p}<0,001)^{8}$. Asimismo, otros estudios también comprobaron la efectividad del método en la visualización de la disección del borde, el pro- 


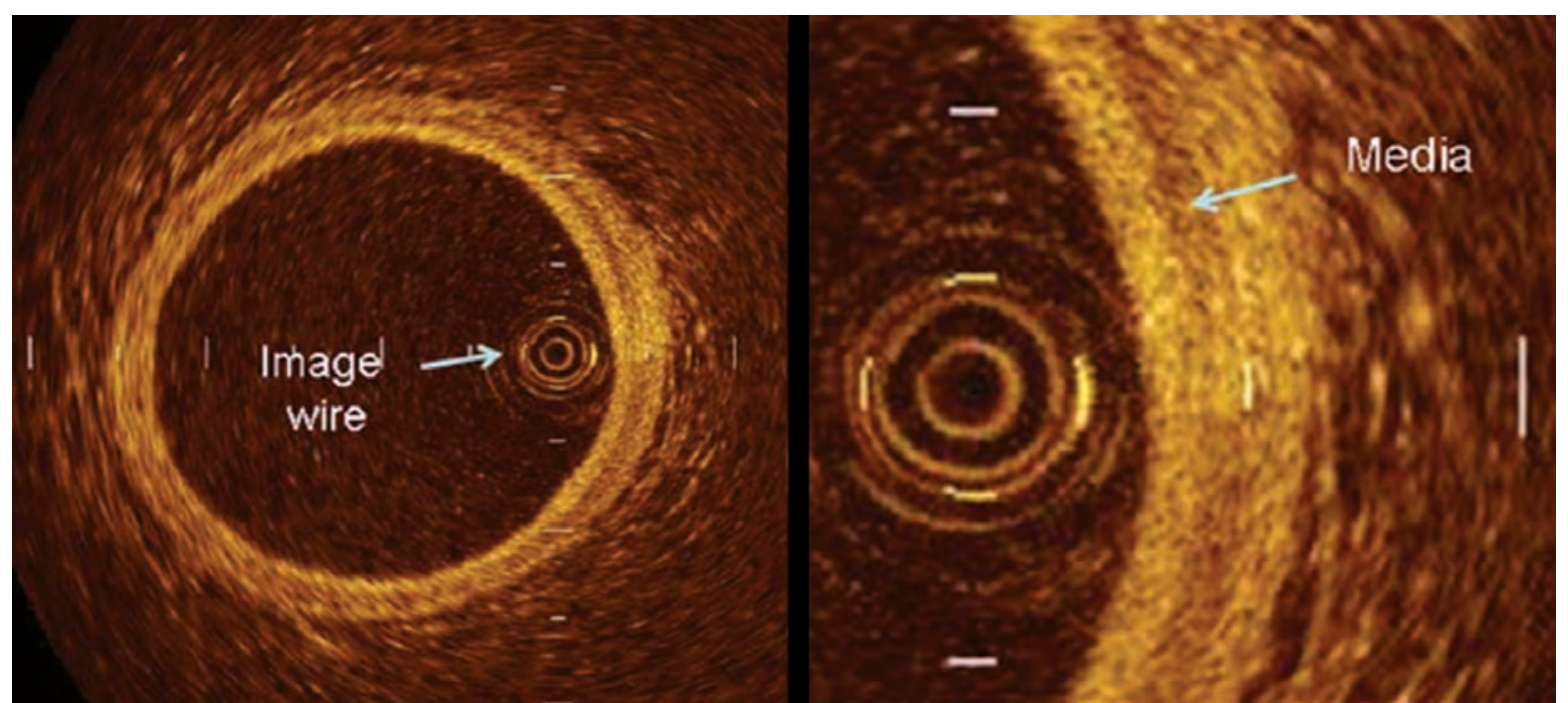

Figura 1. Estructura normal de la pared del vaso por OCT: Estructura de 3 capas con túnica media observada como señal de baja intensidad limitada por lámina interna y externa. Imagen modificada de la referencia 6.

lapso tisular, la disección en el stent y la mala aposición. Los valores de kappa para la coincidencia entre estudios, entre observadores y en el observador en la caracterización de la placa fueron $0,92,0,82$ y 0,95 , respectivamente ${ }^{7}$.

\subsection{Evaluación de la enfermedad coronaria por OCT}

\subsubsection{Morfología coronaria normal}

La pared coronaria normal tiene una estructura de tres capas no mayor de $1,2 \mathrm{~mm}$, por lo que son evaluables por OCT. Se puede observar una capa de túnica media muscular como una banda oscura compuesta por células de baja refringencia, está delimitada en el borde interno por la lámina elástica interna (LEI) y en su borde externo por la lámina elástica externa (LEE). Si bien la LEI histológicamente está compuesta por un capa fina de colágeno inferior a las 3 micras, esta produce una señal de alta intensidad de alrededor de 20 micras fácilmente objetivable por OCT. La LEE también tiene un grosor aproximado de 20 micras y delimita a la túnica media por su interior y la adventicia en el lado externo, donde se observa como una zona de alta intensidad de textura heterogénea rodeando el exterior del $\operatorname{vaso}^{6}$ (Figura 1).

\subsubsection{Evaluación de la severidad de la estenosis coronaria}

Actualmente el patrón oro para el estudio objetivo de estenosis coronaria en lesiones intermedias, que dejen algún grado de duda por angiografía coronaria, es el FFR' . Este método puede estar contraindicado en algunas ocasiones, por ejemplo cuando está contraindicado el uso de adenosina, y es ahí donde la OCT puede ser un método útil para evaluar el grado de lesión. Asimismo, el FFR tiene algunas limitaciones, especialmente al momento de evaluar la severidad de una lesión en un segmento del árbol coronario que muestre múltiples lesiones en tándem ${ }^{10}$.
En ocasiones es necesario utilizar algún método de imagen intracoronaria para evaluar la necesidad de tratamiento de algunas lesiones. La OCT permite visualizar de forma nítida el límite entre la pared del vaso y el lumen, por tanto permite medir el área luminal de forma muy precisa y reproducible ${ }^{11}$.

Uno de los métodos intracoronarios de imágenes más utilizados en la actualidad, validado con ensayos clínicos comparado con FFR, es el IVUS. Este utiliza el área luminal mínima (ALM) para caracterizar la severidad de la estenosis. Diversos estudios han demostrado diferencias entre las mediciones de lumen realizadas con IVUS y OCT ${ }^{7}$. Por lo tanto, los puntos de corte ya establecidos para el IVUS no se pueden aplicar de forma directa a la OCT. En un ensayo realizado por el grupo español del Dr. Gonzalo Nieve para evaluar la eficiencia diagnóstica de la OCT para detectar estenosis con FFR $<0,8$, esta tuvo una eficiencia diagnóstica moderada y un punto de corte óptimo por debajo del establecido hasta ahora para el IVUS ${ }^{12}$. Es posible que otros aspectos como el tamaño del vaso y la masa de miocardio distal a la estenosis en el área luminal mínima tengan un papel fundamental para determinar la relevancia funcional de la estenosis coronaria. Es por esta razón que actualmente se requiere más investigación para poder adaptar alguna escala o puntos de corte óptimos para la OCT.

\subsection{Caracterización de la placa}

Esta tecnología ha abierto todo un nuevo mundo de posibilidades en el estudio de la aterosclerosis coronaria, puesto que nos proporciona con gran detalle información acerca de la composición de la placa u otras características que pueden influir en su tendencia a romperse y producir eventos, actualmente conocidas como "placas vulnerables". Asimismo, es muy sensible para la detección de la causa más frecuente de los síndromes coronarios agudos, que consiste en la ruptura de placa y posterior trombosis. 


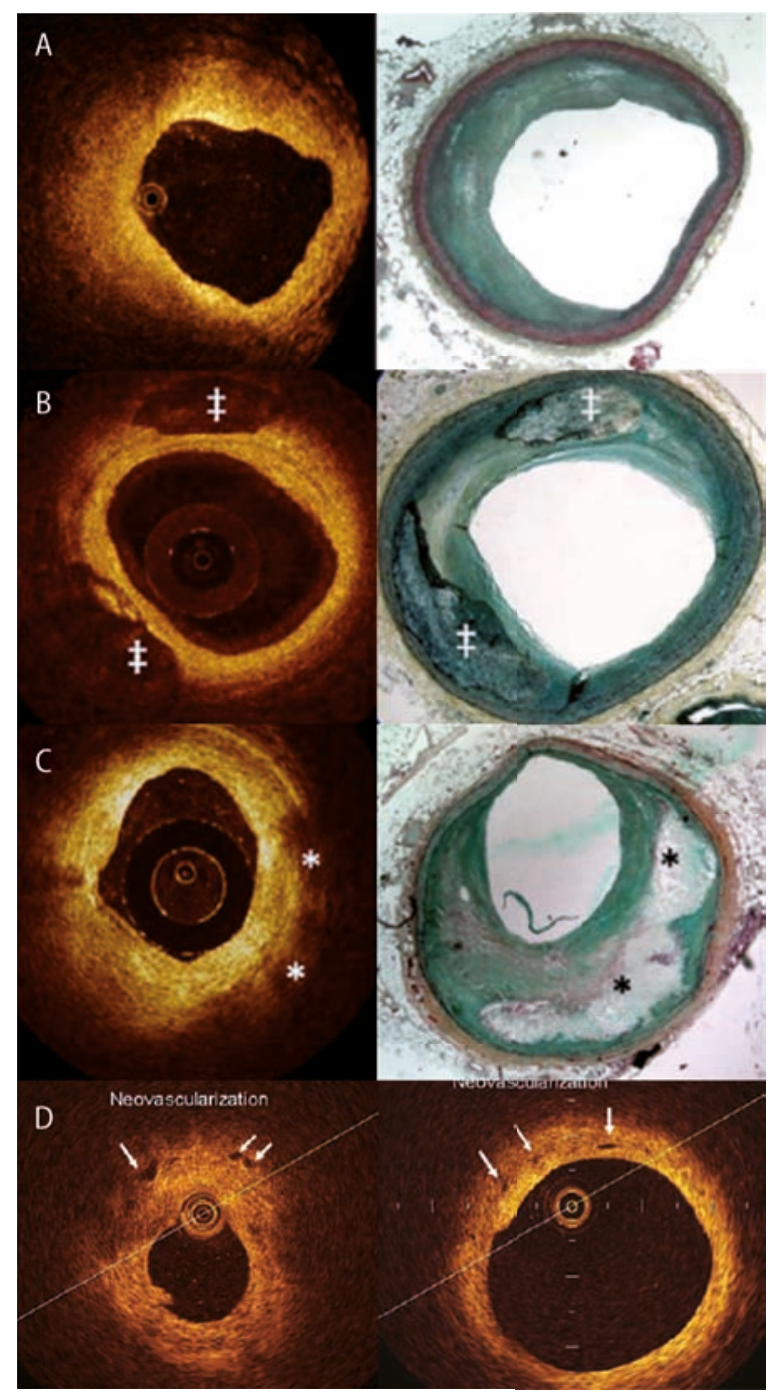

Figura 2. A. Placa fibrótica: zona homogénea de alta reflectividad. B. Placa calcificada: zona de baja reflectividad con bordes muy bien delimitados, permite mayor penetración. C. Placa lipídica con cápsula fibrosa gruesa: zona de baja reflectividad con bordes difusos, permite menor penetración. D. Las flechas muestran neovascularización, diámetro aproximado de 50100 um. \#: Placa cálcica. *: Placa lipídica. Imágenes modificadas de la referencia 51.

La OCT proporciona información acerca de los distintos componentes de la placa. Estos tienen distintas propiedades ópticas y son fácilmente diferenciables por este método. Así es como tenemos 3 tipos fundamentales de placa: 1) La placa fibrosa: zonas homogéneas de alta reflectividad. 2) Placa fibrocalcificada: el calcio se puede visualizar como una zona de baja reflectividad con bordes bien delimitados y, a diferencia del IVUS, la OCT no produce sombra. Por último tenemos 3) las placas lipídicas: zonas de baja reflectividad pero con bordes difusos, difíciles de $\operatorname{precisar}^{13}$ (Figura 2).

Debido a la limitada penetración, especialmente cuando hay componente lipídico, muchas veces la OCT no puede visualizar la placa de forma completa. De esta manera, la OCT no es el método ideal para evaluar el remodelamiento positivo donde otro método como el IVUS, con mayor penetración, sería más útil para evaluar este

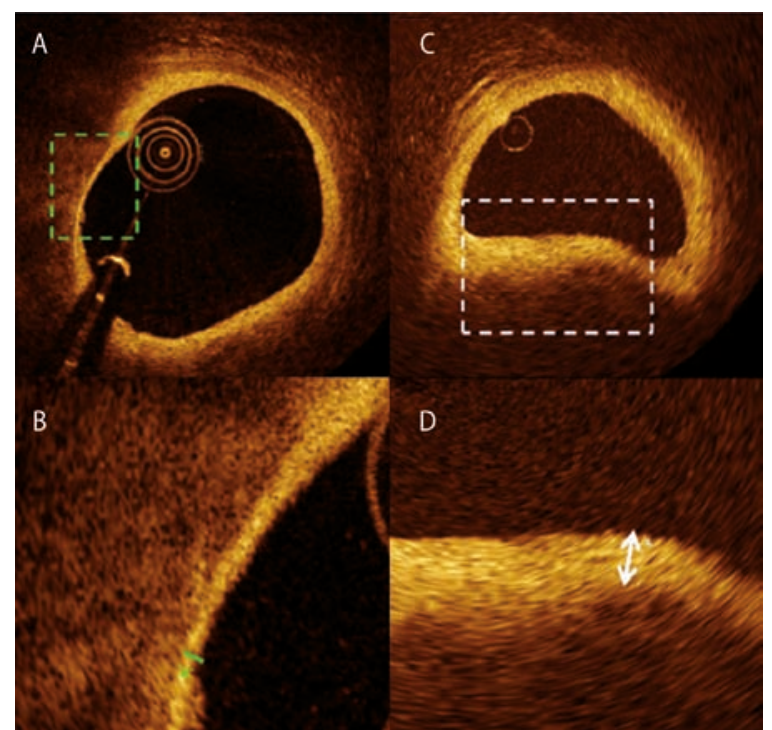

Figura 3. Medición de la capa fibrosa por OCT. A y B muestran capa fibrosa de cubierta fina de $40 \mu \mathrm{m}$. C y D, capa fibrosa de cubierta gruesa de $250 \mu \mathrm{m}$. Imágenes modificadas de la referencia 51.

fenómeno. De igual manera, al otorgarnos una gran resolución de las zonas de la placa cerca de la superficie luminal, la OCT aporta información importante en el momento de la revascularización con stent. Como por ejemplo, la presencia de calcio y su localización pueden indicar la necesidad de utilizar elementos de aterectomía rotacional al momento de planificar la angioplastia.

Una de las principales ventajas de la OCT es la gran sensibilidad que tiene para evaluar la cápsula fibrosa de las placa de ateroma. Múltiples estudios han demostrado que las placas que más frecuentemente se rompen y dan lugar a síndromes coronarios agudos son aquellas con núcleo lipídico-necrótico grande recubierto por una cápsula fibrosa fina de menos de 65 micras. Estas han sido denominadas como fibroateroma de cápsula fina (FACF $)^{14}$. Como dijimos previamente, la resolución axial del IVUS es de 100-150 micras, por lo que no es un método adecuado para evaluar este tipo de lesiones. En cambio, la gran resolución espacial de la OCT permite medir al detalle el grosor de la cápsula fibrosa, y ello permite identificar el FACF con una sensibilidad del $90 \%$ y una especificidad cercana al $80 \%$ en comparación con la histopatología $a^{15,16}$. Si bien la detección de estas placas de alto riesgo podrían ser útiles en la prevención de futuros SCA, hay muchos factores que influyen en la tendencia de una placa a romperse y por tanto necesitamos más información para ser capaces de determinar con más especificidad cuales son los FACF que podrían tener riesgo de producir SCA.

Es aquí donde la OCT se vuelve una de las herramientas con un futuro prometedor, en la prevención de los SCA e incluso en otros campos como en la evaluación del tratamiento médico con estatinas, analizando el remodelado de la cápsula fibrosa y cómo este afecta la estabilidad de la placa (Figura 3). 


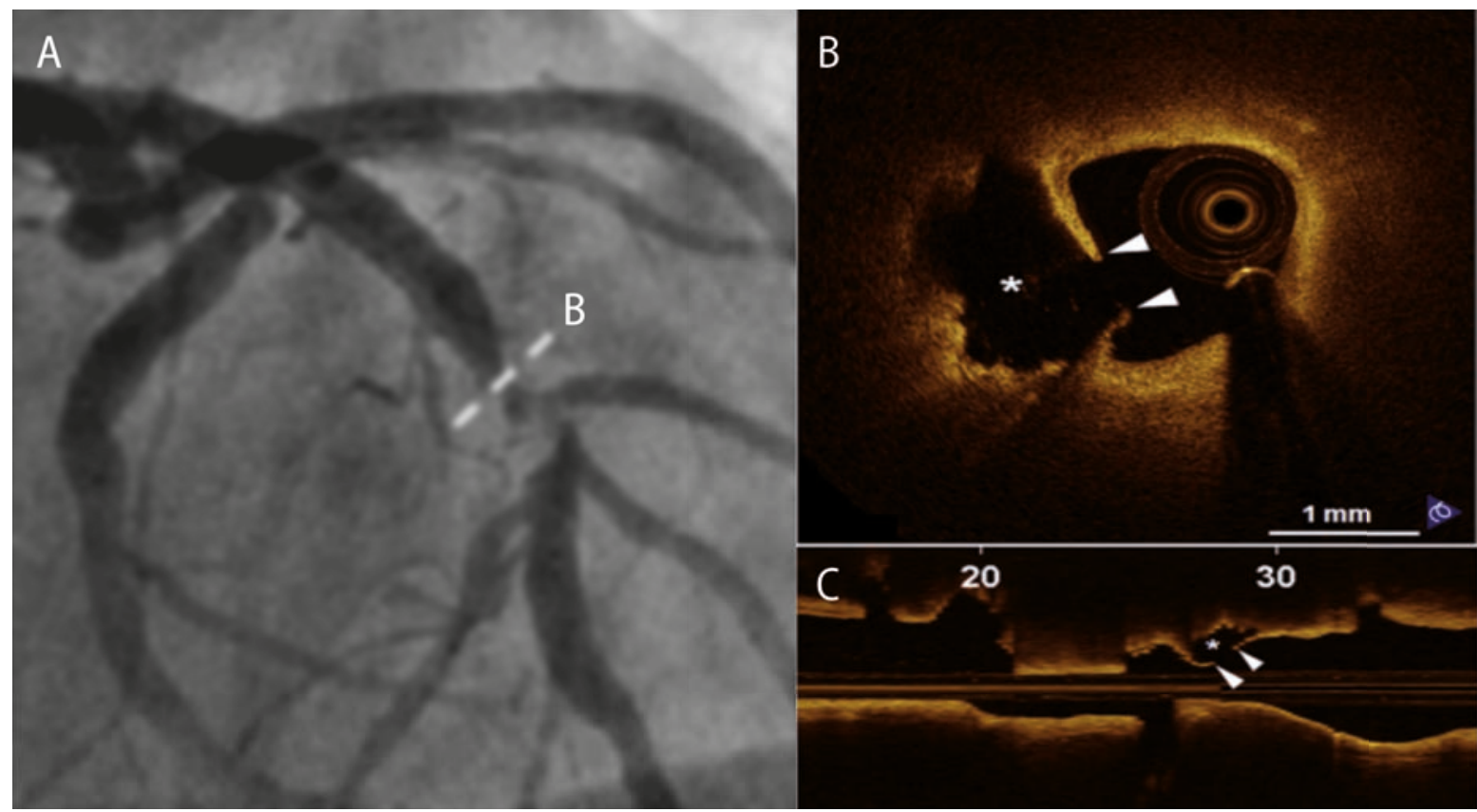

Figura 4. A. Angiografía convencional con lesión culpable (B). B. Ruptura de placa corte transversal. C. Ruptura de placa corte longitudinal. Imágenes modificadas de la referencia 52.

Otros aspectos menos estudiados, pero que de igual manera hablan de la vulnerabilidad de la placa, son la intensa infiltración por macrófagos, los cuales se identifican como zonas delimitadas de alta reflectividad con sombra posterior ${ }^{17}$. La presencia de microvasos o neovascularización es otro factor que podría tener relación con la inestabilidad de la placa (Figura 3).

\subsection{Identificación de la causa de los síndromes coronarios agudos}

La causa más frecuente de los SCA es la ruptura de placa y posterior formación de trombo intraluminal. La OCT identifica con gran precisión la presencia de placas rotas, que se visualizan como zonas donde se observa una disrupción de la cápsula fibrosa y una cavidad que corresponde al material que se ha vertido a circulación (Figuras 4 y 5). Este método también tiene muy alta sensibilidad en la detección del trombo, el cual generalmente se observa como una estructura irregular de alta reflectividad que protruye en el lumen y produce sombra posterior. Como lo describieron Kume T. y colaboradores, según la misma composición del trombo y el efecto de la sombra acústica producida es posible diferenciar dos tipos de trombo, uno en el que la sombra será más pronunciada, llamado trombo rojo, y otro con menos sombra acústica, denominado trombo blanco ${ }^{18}$.

Además de la ruptura de placa tipo FACF se han identificado otros dos tipos de lesiones que con menos frecuencia son causa de SCA: la erosión y el nódulo calcificado. La erosión se define en patología como la formación de trombo en contacto directo con la íntima en una zona denudada de endotelio. Con el uso del OCT podríamos llegar al diagnóstico de erosión cuando evidenciamos presencia de trombo originado en una zona

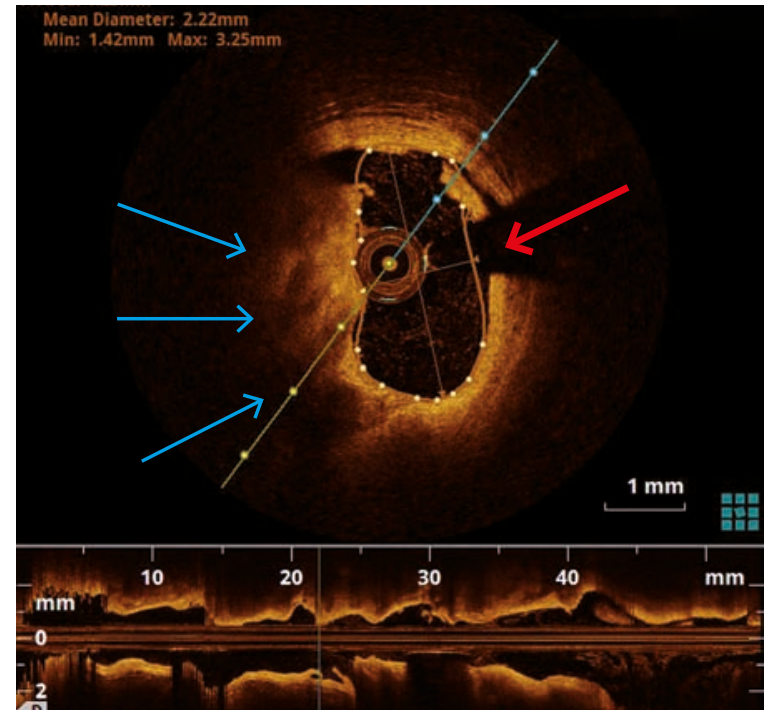

Figura 5. Ruptura de placa. Se puede observar imagen de disrupción del endotelio tanto en el eje longitudinal como en el transversal. La flecha roja indica zona de ruptura entre zona horaria 1-4. Las flechas azules señalan gran placa lipídica con crecimiento hacia la luz del vaso. Imagen: Base de imágenes OCT, Servicio Hemodinamia Sanatorio Otamendi. Paciente MC 05/04/2017.

de la pared sin que exista evidencia de una ruptura de la cápsula fibrosa en la zona adyacente. El nódulo de calcio es una placa calcificada que protruye a la luz con trombo adherido, y se identifica en OCT como una estructura de baja reflectividad con bordes muy bien delimitados, recubierta por una cápsula fibrosa rota y con trombo asociado ${ }^{19}$.

La disección coronaria espontánea (DCE) es una causa menos frecuente de síndrome coronario agudo. En un estudio prospectivo realizado sobre 5002 pacientes cursando SCA, se estudiaron 17 individuos con sospecha DCE por angiografía convencio- 


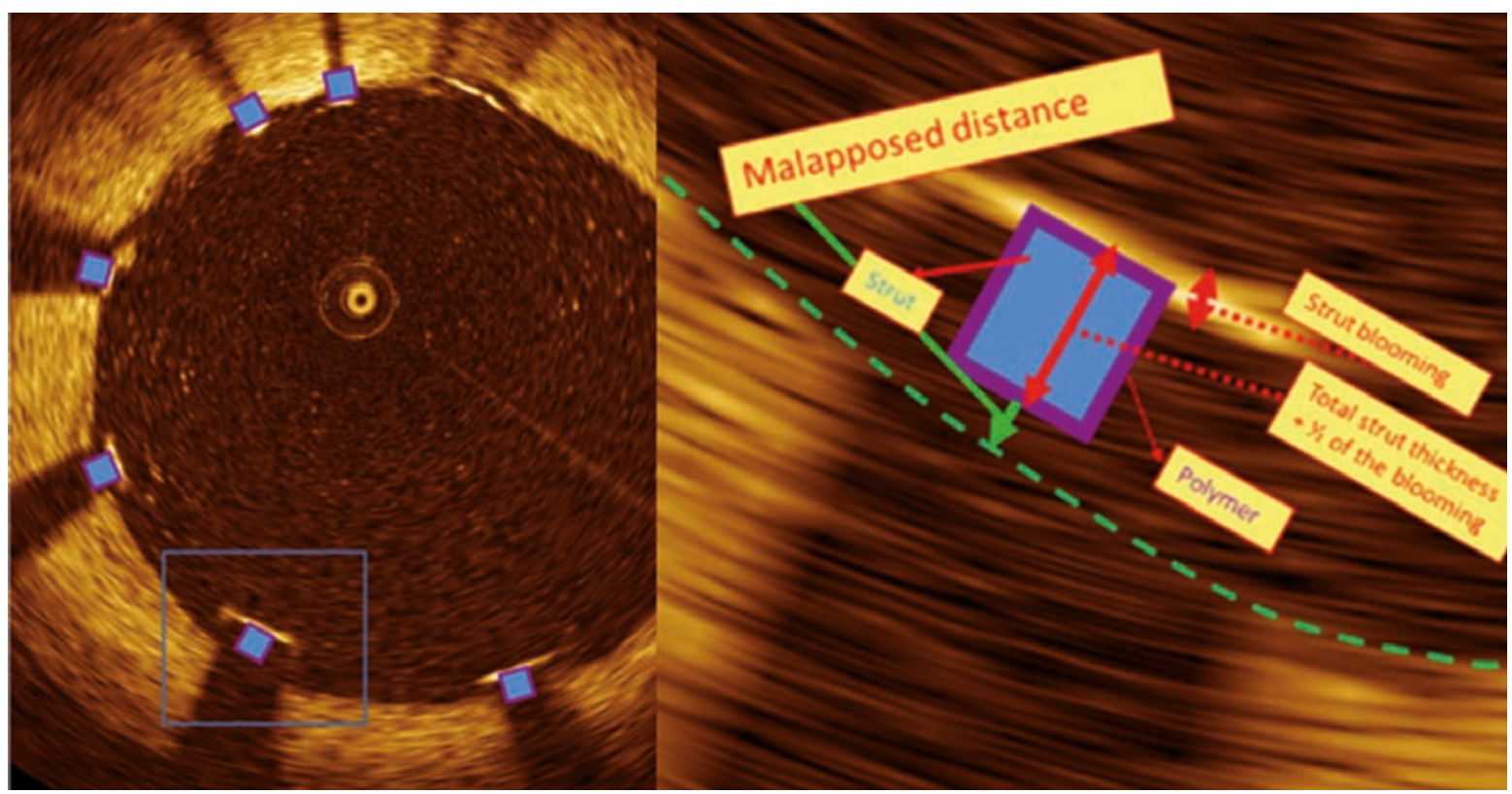

Figura 6. La imagen ilustra mala aposición del stent. La flecha verde muestra cómo la distancia strut y la pared es mayor al del strut. Figura modificada de la referencia 51 .

nal con OCT. Esta descartó la DCE en 6 pacientes y pudo diagnosticar con gran detalle la disección coronaria de los restantes 11 pacientes. Se pudo distinguir el flap de disección en 6 pacientes, medir el largo y ancho de la membrana intimomedial, evaluar el área de luz verdadera $\left(1,1 \pm 0,5 \mathrm{~mm}^{2}\right)$, área de luz falsa $\left(5,9 \pm 2,10 \mathrm{~mm}^{2}\right)$ o incluso si había hematoma intramural o trombo en la luz falsa y/o verdadera. La mayoría de estos hallazgos no fueron evidenciados por la angiografía convencional. Incluso se utilizó la OCT para evaluar la eficacia y seguridad del tratamiento con stent, evaluando la cobertura de la lesión con el stent, la aposición del mismo e incluso el hematoma intramural residual luego del implante del stent. Este ensayo concluye que la OCT es una herramienta fundamental en el diagnóstico temprano y en el manejo de este tipo de lesiones vasculares ${ }^{20}$.

\subsection{Guía durante el procedimiento percutáneo y en el seguimiento}

\subsubsection{Tras la implantación del stent}

El OCT evalúa de forma detallada la interacción entre el stent y la pared vascular. Debido a que los struts metálicos son opacos a la luz, solo la superficie de los stents es observada con claridad. Hay 2 hallazgos que permiten observar los struts del stent, generalmente se observan como puntos de alta reflectividad con gran sombra posterior; con visualizar alguna de estas dos características ya es suficiente para su identificación. Los parámetros que pueden evaluarse luego del implante del stent son los siguientes: 1) Prolapso: se define como la protrusión del tejido entre los struts adyacentes sin evidencia de ruptura de la superficie luminal. 2) Aposición: puede definirse que un strut se en- cuentra con mala aposición cuando la distancia entre este y la pared es mayor a del espesor del strut (Figura 6). 3) Presencia de trombo, que puede observarse protruyendo entre los struts o por encima de estos. 4) Disección: son zonas de discontinuidad de la superficie luminal dentro o incluso en los bordes del stent.

\subsubsection{En el seguimiento luego de angioplastia coronaria}

La OCT puede evaluar de forma muy detallada la aposición del stent a la pared vascular en el seguimiento. De esta forma, podemos tener distintas formas de mala aposición. Esta puede ser persistente, cuando ya se encontraba presente tras la implantación o adquirida cuando aparece durante el seguimiento (Figura 7).

Múltiples estudios han evaluado la superioridad de la OCT con respecto al IVUS en la determinación de mala aposición del stent en el seguimiento y posintervención inmediata ${ }^{21,22}$. Esta puede ser un gran aporte de la OCT al mundo de la revascularización por stent, debido a que efectos como la mala aposición del stent han sido ya relacionados a mayores tasas de reestenosis y stent trombosis en estudios realizados por IVUS ${ }^{23-25}$. Uno de los precursores en describir este fenómeno fue el grupo de Cook S. y cols. en el año 2007. Con el uso del IVUS, ellos evaluaron un grupo de pacientes con stent trombosis muy tardía, luego de los 2 años del implante del stent farmacológico, comparados con un grupo control. Se observó mala aposición del stent en un $77 \%$ de los casos vs. $12 \%$ del grupo control $(\mathrm{p}<0,001)^{26,27}$. De igual manera, es importante resaltar que hasta el momento ninguno de ellos ha podido traducir estos beneficios a end-points clínicos duros tales como menor tasa de IAM, ACV o muerte. 


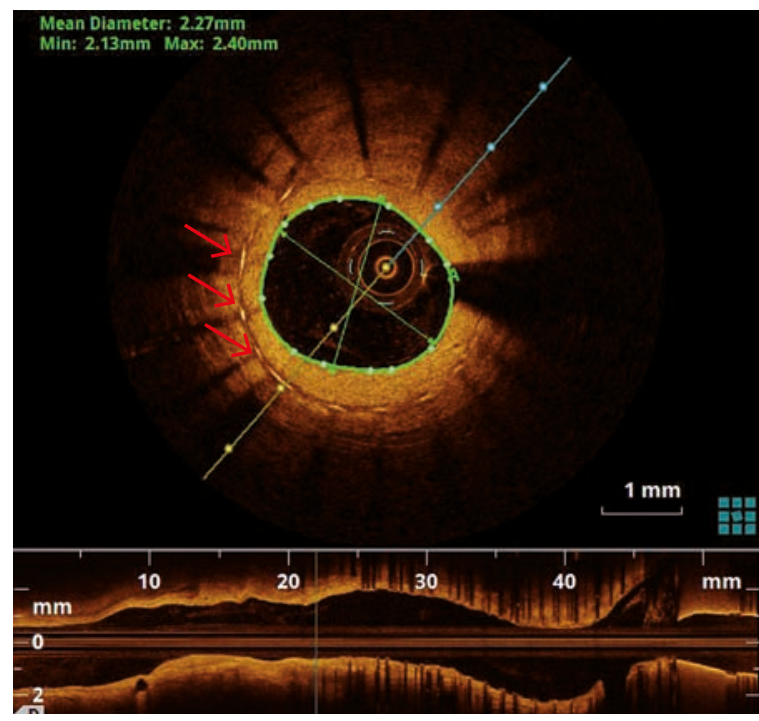

Figura 7. Imagen OCT de seguimiento stent metálico a 10 meses del implante. Se observa imagen de alta reflectividad con gran sombra posterior (flecha roja) correspondiente a los stents. El círculo verde corresponde a luz verdadera del vaso. La línea azul mide zona de hiperplasia neointimial en zona del implante del stent. Imagen: Biblioteca de imágenes OCT, Servicio de Hemodinamia del Sanatorio Otamendi, Paciente D.V. 17/4/2017.

Un subestudio reciente del HORIZONS (Harmonizing Outcomes with Revascularization and Stents in AMI) evaluó 117 pacientes con SCACEST (síndrome coronario agudo con elevación del ST) de forma prospectiva, aleatorizada y ciega. Se realizó seguimiento a los 13 meses con OCT de pacientes revascularizados con stents convencionales $v s$ stents farmacológicos, y se observó que si bien los stent medicamentosos bajan de forma considerable la hiperplasia neointimal estos tienen mayor tasa de struts con mala aposición respecto de los stents convencionales ${ }^{28}$.

\section{DISCUSIÓN}

\subsection{Utilidad clínica en la actualidad}

\subsubsection{Placa vulnerable}

Hace un par de décadas, solamente se podía ver con detalle el sustrato anatómico de las oclusiones trombóticas agudas en estudios ex vivo. En una serie de $200 \mathrm{ca}-$ sos de muerte súbita, en el $60 \%$ la causa fue ruptura de un $\mathrm{FACF}^{29}$. Este tipo de placa es el que hoy conocemos como placa vulnerable y está caracterizado por 3 elementos fundamentales. Un gran núcleo lipídico compuesto por colesterol libre, células espumosas, cristales de colesterol, hemorragia, microcalcificaciones, cubierta por una delgada capa fibrosa generalmente menor a los 65 micrones compuesta por células musculares lisas. Por último, se suele observar en estudios histológicos una densa infiltración de macrófagos, que digieren la media y favorecen al remodelado positivo ${ }^{30}$.

La relevancia clínica en tener un método diagnóstico que nos permita detectar con eficacia y seguridad este tipo de placas es un campo de estudio de amplio debate en la actualidad. La estratificación del riesgo convencional predice solo un $65-85 \%$ de los eventos de SCA. En un estudio realizado en Japón publicado en el año 2008, se demostró cómo apenas el 25\% de los pacientes menores de 65 años que debutan con un SCA habrían clasificado para tratamiento con estatinas según el score de Framingham ${ }^{31}$.

Por otro lado, en el campo de la prevención secundaria, el estudio PROSPECT analizó 697 pacientes donde se realizó el estudio de todo el árbol coronario mediante IVUS a pacientes con SCA de forma prospectiva. A un seguimiento promedio de 3 años, tuvieron una tasa de eventos cardiovasculares mayores de 20,4\%, de los cuales en el $12.9 \%$ las lesiones culpables eran las causantes del nuevo evento y un $11.6 \%$ de eventos eran en lesiones no culpables. La mayoría de lesiones no culpables accidentadas en el seguimiento habían tenido por angiografía convencional un diámetro de estenosis del $30 \pm 20,6 \%$. Realizando un análisis multivariado pudieron identificar que en los casos de lesiones no culpables había 3 predictores de eventos adversos caracterizadas por IVUS. Estos eran la carga de placa mayor al $70 \%$ (hazard ratio $[\mathrm{HR}]=5,03 \%$; intervalo de confianza del 95\% [IC95\%]: 2,5-10,11; $<<0,001$ ), lesiones con FACF ( $\mathrm{HR}=3,3$; IC95\%: 1,77-6,36; $\mathrm{p}<0,01)$ $y$ tener el ALM menor de $4,0 \mathrm{~mm}^{2}(\mathrm{HR}=3.21$; IC95\%: 1,61-6,42; $\mathrm{p}=0,001)^{32}$ (Figura 8).

A pesar que los FACF son el sustrato de las oclusiones trombóticas en aproximadamente $60 \%$ de los casos, hay otros sustratos patológicos para los SCA. Un estudio reciente realizado con OCT preintervención en 126 pacientes cursando SCA confirmó a la ruptura de placa como la causa más frecuente. Se describieron 3 causas fisiopatológicas principales que desencadenarían los SCA: la ruptura de placa, presente en el 43,7\%; la erosión de placa, en el 31\%; y el nódulo calcificado, en el $7,9 \%$. Asimismo, se observó que los pacientes que presentaron erosión de placa eran más jóvenes comparados con aquellos de ruptura de placa. Otro aspecto fundamental fue que, comparada con la ruptura de placa, la presentación como síndrome coronario agudo sin elevación del ST (SCASEST) era más común en pacientes con erosión de placa $(61,5 \%$ vs. 29.1\%; $\mathrm{p}=0.008)$ y nódulo calcificado ( $100 \%$ vs. $29,1 \%$; $\mathrm{p}<0,001)$.

Una de las principales limitaciones acerca de las ventajas que nos puede llegar a brindar la OCT con respecto a la identificación de las placas vulnerables y su debido tratamiento está en el poco conocimiento acerca de la historia natural de estas lesiones. No toda placa vulnerable se accidenta y desencadena un evento clínico. En el año 2002, Rioufol y colaboradores publicaron un estudio que evaluó por primera vez la prevalencia de la ruptura de placa en pacientes SCA utilizando IVUS en los tres vasos. Ellos encontraron un promedio de 2,1 placas rotas por paciente. Un dato más interesante fue que cerca del $80 \%$ de los pacientes presentaron placas rotas fuera de la lesión culpable y cerca del $70 \%$ en vasos no culpables ${ }^{33}$. 
TABLA 2. Eventos clínicos a 1 año.

\begin{tabular}{|l|c|c|c|c|}
\hline & $\begin{array}{c}\text { Guiado } \\
\text { por IVUS } \\
(\mathbf{n}=3349)\end{array}$ & $\begin{array}{c}\text { Guía an- } \\
\text { giográfica } \\
(\mathrm{n}=5234)\end{array}$ & $\begin{array}{c}\text { Hazard ratio } \\
\text { no ajustado } \\
(\text { IC95\%) }\end{array}$ & $\mathrm{p}$ \\
\hline $\begin{array}{l}\text { Stent trombosis definitiva } \\
\text { o probable }\end{array}$ & $0,6 \%(18)$ & $1 \%(53)$ & $0,53(0,31-0,90)$ & 0,02 \\
\hline MACE & $3,1 \%(103)$ & $4,7 \%(238)$ & $0,67(0,53-0,84)$ & 0,0006 \\
\hline - Temprana (0-30 días) & $1,6 \%(53)$ & $2,1 \%(109)$ & $0,76(0,55-1,05)$ & 0,10 \\
\hline - Tardía (30 días-1 año)) & $1,7 \%(55)$ & $2,7 \%(133)$ & $0,64(0,47-0,87)$ & 0,005 \\
\hline Muerte & $1,8 \%(58)$ & $2 \%(103)$ & $0,87(0,63-1,2)$ & 0,40 \\
\hline $\begin{array}{l}\text { Infarto agudo de miocar- } \\
\text { dio (IAM) }\end{array}$ & $2,5 \%(81)$ & $3,7 \%(188)$ & $0,67(0,51-0,87)$ & 0,002 \\
\hline - Periprocedimiento & $1,3 \%(42)$ & $1,6 \%(81)$ & $0,82(0,57-1,19)$ & 0,26 \\
\hline $\begin{array}{l}\text { - IAM relacionado al vaso } \\
\text { tratado }\end{array}$ & $1,7 \%(55)$ & $2,9 \%(148)$ & $0,58(0,42-0,79)$ & 0,0004 \\
\hline TLR isquémico & $1,5 \%(51)$ & $2,4 \%(124)$ & $0,64(0,46-0,88)$ & 0,0007 \\
\hline TVR isquémico. & $2,4 \%(81)$ & $4,0 \%(207)$ & $0,60(0,17-0,78)$ & 0,0001 \\
\hline
\end{tabular} $\begin{aligned} & \text { MACE: eventos cardiovasculares mayores. TLR: revascularización lesión tratada. TVR: re- } \\
& \text { vascularización vaso tratado. Tabla modificada del estudio ADAPT-DES. MACE significati- } \\
& \text { vamente menor en el grupo de angioplastia guiaqda por IVUS (referencia 36). }\end{aligned}$

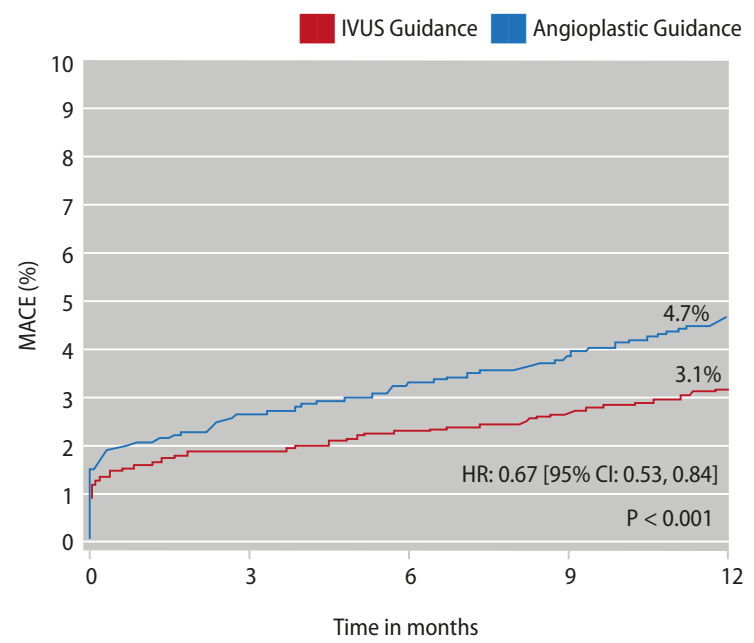

\begin{tabular}{|l|c|c|c|c|c|}
\hline \multicolumn{5}{|l|}{ Number at risk } \\
\hline$\square$ & 3349 & 3206 & 3168 & 3138 & 2966 \\
\hline$\square$ & 5234 & 4930 & 4878 & 4826 & 4457 \\
\hline
\end{tabular}

Con lo evaluado hasta el momento podemos ver entonces algunas limitaciones que oscurecen el potencial impacto clínico en la pesquisa invasiva de la placa vulnerable: la alta prevalencia de las placas de alto riesgo o cómo no todos los FACF se rompen y no muchas rupturas de placa desencadenan eventos clínicos. Otra desventaja está en que alrededor de un $40 \%$ de las trombosis agudas no tienen como sustrato la ruptura de placa sino otros mecanismos fisiopatológicos.

De igual manera podemos argumentar que la mayoría de estos estudios realizados en el campo de los SCA han utilizado IVUS como método diagnóstico y ya conocemos las ventajas que nos brinda la alta resolución del OCT sobre el IVUS. Tal como lo demostraron Kubo y colaboradores en un estudio que comparó OCT, IVUS y angioscopia coronaria en pacientes con infarto agudo de miocardio, la OCT tiene una mayor sensibilidad para detectar fenómenos agudos sobre las placas accidentadas. Ellos demostraron que la incidencia de ruptura de placa fue observada en mayor canti- dad de casos por la OCT comparada con el IVUS de forma significativa ( $73 \%$ vs. $40 \%$; $\mathrm{p}=0,009)$. Asimismo, la OCT fue una herramienta mucho más efectiva para la identificación de erosión de placa respecto del IVUS. Esta se observó en el $23 \%$ de pacientes por OCT, mientras que no fue posible detectar este fenómeno en ninguna placa por IVUS.

En este mismo estudio se pudo llegar a visualizar el trombo con gran detalle, en todos los casos del uso de OCT, debido a las propiedades de ecogenicidad neutra del trombo; este solo se pudo observar con IVUS en el $33 \%$ de pacientes.

\subsubsection{Optimización del implante del stent}

Actualmente se demostró que el grado de expansión del stent medido por área mínima del stent luego del procedimiento percutáneo es el predictor más importante para predecir eventos de reestenosis y stent trombosis ${ }^{34}$. Múltiples trabajos demuestran que al utilizar el IVUS como guía para la correcta aposición del stent hay una mejoría al seguimiento en la tasa de eventos clínicos. Un metaanálisis que comparó el uso del IVUS vs. la angiografía convencional en 26.503 pacientes de 14 estudios observacionales y 3 estudios aleatorizados con implante de stent farmacológico demostró que el IVUS tenía superioridad en el seguimiento en cuestión de TLR (target lession revascularization) ( $\mathrm{OR}=0,81$; IC95\%: 0,66$1,0 ; \mathrm{p}=0,04)$, muerte (OR=0,61; IC95\%: 0,48$0,79 ; \mathrm{p}<0,001)$, infarto $(\mathrm{OR}=0,57$; IC95\%: 0,41 $0,75 ; \mathrm{p}<0,001)$ y stent trombosis $(\mathrm{OR}=0,59$; IC95\%: $0,47-0,75 ; \mathrm{p}<0,001)^{35}$.

Estos resultados son similares a los obtenidos en el ADAPT-DES Study, estudio prospectivo, multicéntrico, no aleatorizado all-comers sobre el uso de IVUS en el tratamiento percutáneo de 8583 pacientes con stent farmacológico (Tabla 2). En este estudio además se observan los mayores beneficios en pacientes con lesiones complejas y en la población con SCA ${ }^{36}$.

Por lo previamente explicado, la OCT tiene una mayor capacidad de resolución comparada con el IVUS ${ }^{15,37}$. El estudio ILUMEN II, uno de los mayores en comparar el procedimiento percutáneo guiado por IVUS u OCT, concluyó que no hubo mayores diferencias en el grado de expansión del stent utilizando ambos métodos como herramienta para el implante, aunque se pudo evidenciar por OCT mayor cantidad de disección, prolapso de tejido y mal aposición del stent de grados leves ${ }^{38}$ (Figura 9).

En el estudio aleatorizado y multicéntrico DOCTORS (Does Optical Coherence Tomography Optimize Results of Stenting), se realizó OCT pre- y posimplante de stent en 240 pacientes con SCASEST, hubo un cambio en la conducta del médico tratante en el $50 \%$ del grupo guiado por OCT. También se encontró un beneficio en el punto final primario, el cual fue mejor resultado funcional de la angioplastia evaluado por FFR a expensas de utilización de mayor cantidad de contraste y tiem- 


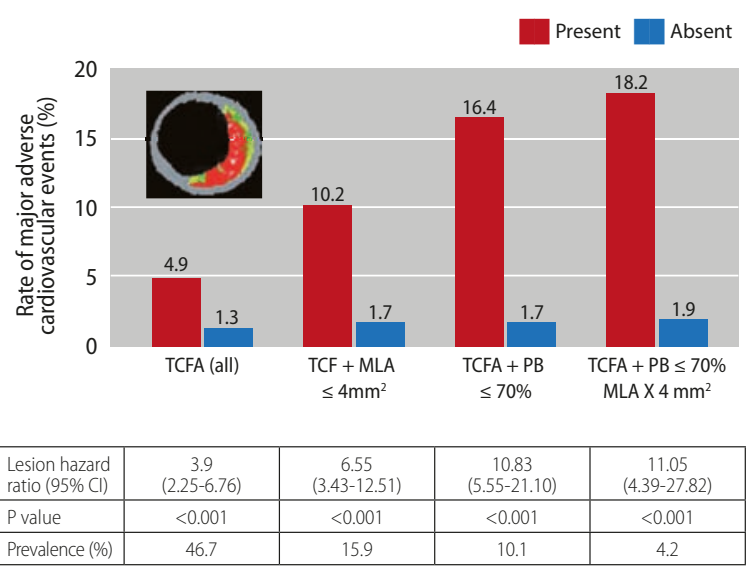

Figura 8. Predictores de vulnerabilidad de placa. TCFA: fibroateroma de Cubierta fina. MLA: área luminal mínima. PB: carga de placa. Figura modificada de PROSPECT study.

po de fluoroscopia, sin diferencias en cuanto a daño renal ni IAM periprocedimiento ${ }^{39}$. Otro estudio evaluó el uso de la OCT en pacientes con IAM con supradesnivel del ST. El estudio observó una diferencia significativa en la expansión del stent implantado mediante guía por OCT respecto de la angiografía convencional, utilizando el diámetro luminal minimo (DLM) como referencia. Asimismo este estudio no observó diferencias en su punto final primario, el cual fue el compuesto de muerte, IAM, stent trombosis y revascularización de vaso culpable al año. Ellos argumentan que al tener una tasa muy baja de eventos cardiovasculares observados en el grupo angiográfico (9,6\% al año), el estudio, que solo contó con la inclusión de 642 pacientes, tuvo poca potencia para demostrar diferencias significativas. No obstante, se logró evidenciar una clara tendencia a mejoría con respecto al uso de la $\mathrm{OCT}^{40}$.

$\mathrm{Si}$ bien todos estos resultados evaluados hasta la fecha son alentadores para el uso de la OCT, es necesario en la actualidad realizar mayor cantidad de estudios aleatorizados que permitan evaluar y comparar las diferencias en los puntos finales clínicos respecto de la angioplastia guiada por OCT. De esa manera podremos evaluar si aporta mayores beneficios a los que ya nos aporta el tratamiento guiado por IVUS o si hay poblaciones especiales como las del SCA con o sin elevación del ST donde esta herramienta pueda ser de mayor utilidad.

\subsection{Utilidad en investigación clínica}

\subsubsection{Estudios eficacia y seguridad de nuevos stents bioabsorbibles}

Los stents bioabsorbibles han emergido últimamente en el campo de la cardiología intervencionista. Distintos estudios demostraron como la inadecuada endotelización lleva a mayor número de struts no cubiertos, lo cual es un predictor independiente de stent trombo$\operatorname{sis}^{41}$. Estos stents fueron creados con el objetivo de absorberse completamente y así mejorar el grado de dis-

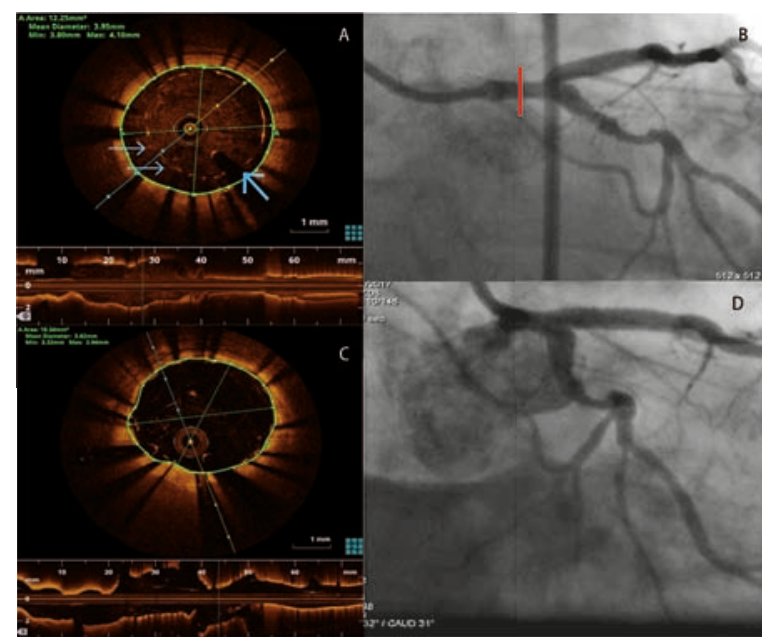

Figura 9. Optimización de implante de stent en angioplastia compleja de tronco común izquierdo. A. Imagen OCT posimplante inmediato de stent a TCI. Se observa (flecha azul) halo de struts con mala aposición. B. Imagen angiográfica posangioplastia inmediata de TCO con técnica Culotte. La línea roja muestra punto de corte aproximado del OCT. C. OCT Luego de POT (proximal optimization technique) con adecuada implantación del stent. D. Imagen an giográfica posdilatación de stent en TCI. Imagen: Base de datos OCT, Servicio de Hemodinamia, Sanatorio Otamendi. Paciente OE 04/07/2017.

función endotelial y disfunción de motilidad que llevan el implante del stent sobre los segmentos tratados. Un estudio comparó cómo la respuesta vasomotora frente a la acetilcolina en pacientes con stent bioabsorbible liberador de everolimus (BVS ABSORB) está relacionada con la composición de la placa evaluada en el seguimiento a 12 y 24 meses $^{42}$. Es así como el implante de estos stents con la recuperación de la fisiología vascular pudo ser demostrada a corto plazo en múltiples ensayos $^{42,43}$. Sin embargo, este beneficio, al igual que el agrandamiento del vaso por absorción de la placa, no se mantuvo en estudios a más largo plazo.

La OCT cumplió un papel fundamental en evaluar la seguridad y eficacia de estos stents. En un subestudio del ABSORB trial, el cual utilizó un stent bioabsorbible liberador de everolimus (BVS), se evaluó la adecuada expansión y endotelización en vivo de los stents, el cual se correlacionó a los buenos resultados obtenidos a nivel de puntos finales clínicos con seguimiento a dos años ${ }^{44-46}$. En este tipo de estudios, la OCT otorga la gran ventaja de poder evaluar no solamente con detenimiento la endotelización sino que, al no haber struts metálicos, permite evaluar de forma única la absorción y la respuesta local del tejido al material del stent ${ }^{45}$. Es así como esta puede ser clave en la futura elaboración y perfeccionamiento de este tipo de tecnología. Sin embargo, estudios recientes han sugerido que estos potenciales beneficios frente a los DES de última generación en el seguimiento a largo plazo no se han mantenido. Los distintos metaanálisis no logran encontrar diferencias significativas en cuestión de tasas de muerte y revascularización ${ }^{47}$, aunque la incidencia de stent trombosis definitiva y probable fueron significativamente mayores con el stent bioabsorbible ${ }^{48}$ 


\subsubsection{Estudios en tratamiento de estatinas y estabilidad de placa}

El rol de las estatinas en reducir las lipoproteínas y marcadores inflamatorios que participan en la enfermedad aterosclerótica ya es conocido. Estas demostraron incluso disminuir la morbimortalidad de los pacientes con enfermedad coronaria. Así se demostraron cómo las terapias más intensivas con dosis igual a mayores a $20 \mathrm{mg}$ de atorvastatina, la estatina más estudia$\mathrm{da}$, tienen incluso beneficio que dosis menores ${ }^{49}$.

Sin embargo, el mecanismo por el cual las estatinas estabilizan la placa no está del todo comprendido y múltiples ensayos se han elaborado para demostrar el llamado efecto pleiotrópico que tienen las estatinas sobre las placas de ateroma. Uno de los estudios donde se comparó mediante un método de imagen el efecto de las estatinas en la estabilización de la placa fue el estudio REVERSAL, un ensayo clínico aleatorizado, multicéntrico, doble ciego, donde se evaluó la progresión de las placas de ateroma a los 18 meses en 508 pacientes utilizando el IVUS. Este demostró como el tratamiento intensivo con dosis de $80 \mathrm{mg}$ de atorvastatina reducían de forma significativa el volumen de placa ${ }^{50}$. Si bien ello fue un gran avance en comprender cómo las estatinas estabilizan la placa, estaba presente la gran limitación de no poder caracterizar con gran detalle la morfología de la placa y evaluar la capa fibrosa.

Como ya mencionamos previamente en el tratado, el ancho de la capa fibrosa es un predictor importante al evaluar la vulnerabilidad de la placa. Debido a su alta resolución, únicamente la OCT puede en la actualidad brindarnos información acerca de este elemento tan importante para entender la progresión y el efecto que tienen las estatinas sobre la capa fibrosa ${ }^{16}$.

El grupo japonés de Takarada y colaboradores realizó un trabajo en pacientes con síndromes coronarios agudos y seguimiento a 9 meses de las placas no culpables ricas en lípidos con OCT. Ellos dividieron a la población en 2 grupos, un grupo de tratamiento con estatinas y un grupo control el cual no contó con tratamiento debido a decisión del paciente o por haber presentado un evento adverso. En este estudio, el seguimiento con IVUS no demostró una disminución significativa en la carga de placa, pero al analizar el cambio del grosor de la capa fibrosa por OCT se encontraron diferencias significativas al seguimiento. Ellos observaron que el grupo con estatinas aumentó el grosor de $110 \mu \mathrm{m}$ basal a $320 \mu \mathrm{m}$ en 9 meses. Comparado con el grupo control, el porcentaje de aumento de grosor de la capa fibrosa fue significativamente mayor $(188 \pm 64 \%$ vs. $117 \pm 39 \%$; $\mathrm{p}<0,001)$. Un punto interesante es que ellos separaron a los pacientes del grupo estatinas en un grupo con capa fibrosa fina (<mediana) y un grupo capa fibrosa gruesa $(>$ mediana). El grupo con capa fibrosa fina tuvo un cambio en el grosor significativamente mayor que el grupo de capa fibrosa gruesa.
Estos hallazgos son similares a los publicados en el estudio EASY-FIT en el año 2014. El punto final primario de este trabajo evaluó los cambios de la capa fibrosa en un grupo intensivo con $20 \mathrm{mg}$ de atorvastatina $v s$. un tratamiento conservador de $5 \mathrm{mg}$ por día. Ellos realizaron seguimiento a 12 meses con OCT y demostraron que hubo un aumento significativo en el grosor de la capa fibrosa en el grupo de tratamiento intensivo con respecto al de $5 \mathrm{mg}$ por día (69 vs. 17\%, respectivamente; $\mathrm{p}<0,001)$.

La habilidad única que tiene la OCT para evaluar con gran detalle el grosor de la cápsula fibrosa y otras características de las placas vulnerables predictores de eventos adversos la convierte en una herramienta vital para ver qué rol cumplen las estatinas en estabilizar la placa y de esa manera prevenir mayor tasa de eventos cardiovasculares.

\section{CONCLUSIONES}

La tomografía de coherencia óptica es una herramienta que se ha ido perfeccionando desde su desarrollo a principios de los años noventa, pasando desde la técnica oclusiva con una velocidad de barrido más lenta, por lo cual su uso se limitaba a segmentos cortos para evitar la isquemia, a la técnica actual con pullback, 10-20 veces más rápida. Se simplifica así la técnica y se torna aplicable a la práctica diaria en el laboratorio de hemodinamia, si bien hoy en día todavía nos encontramos con algunas limitaciones como evaluar lesiones ostiales de tronco común izquierdo y arteria coronaria derecha.

El rol actual de la OCT en el diagnóstico y tratamiento de la enfermedad coronaria está en pleno desarrollo. Como ya hemos descripto, esta ofrece durante el implante del stent la posibilidad de evaluar la aposición con gran detalle y puede identificar con mayor resolución que otras técnicas invasivas la presencia de daño en el vaso debido al implante del stent. En la actualidad ya contamos con estudios que demuestran cómo el implante guiado por OCT brinda ventaja respecto de la angiografía convencional y tiene efectos similares con ligera ventaja respecto al IVUS. Sin embargo, todavía es necesario contar con más estudios clínicos aleatorizados, prospectivos, para sustentar esta estrategia con mayor evidencia. De igual manera, la OCT ya se encuentra dentro de las distintas guías del tratamiento percutáneo para la evaluación del correcto implante del stent en ocasiones específicas.

Uno de los campos donde mayor ventaja otorga esta tecnología es en el seguimiento del intervencionismo percutáneo. Este es el mejor método para evaluar el recubrimiento de los struts y los patrones de hiperplasia neointimal que desarrollan los distintos tipos de stents. La relevancia clínica de esta información ya ha sido demostrada en lo que respecta a eventos cardiovascula- 
res tan serios como la stent trombosis y la reestenosis. Incluso esta información puede ser vital, en ocasiones, cuando es necesario suspender la antiagregación plaquetaria antes del año del implante.

En cuanto a la evaluación de la aterosclerosis coronaria, la OCT es una técnica prometedora en la identificación de placas de alto riesgo. Esta es capaz de proporcionar información acerca de la composición de la placa, además de ser la única de las técnicas invasivas en poder brindar información acerca del contenido de macrófagos y el grosor de la capa fibrosa. Esta última probablemente es el predictor más importante en la vulnerabilidad de la placa.

\section{BIBLIOGRAFÍA}

1. Yusuf S, Reddy S, Ônpuu S, Anand S. Clinical Cardiology: New Frontiers Global Burden of Cardiovascular Diseases. Am Hear Assoc J. 2001;(C):2746-2753. doi:10.1161/hc4601.099487.

2. Nossaman B, Scruggs B.A, Nossaman V.E. MS., et al History of Right Heart Catheterization: 100 Years of Experimentation and Methodology Development. Cardiol Rev. 2010;18(2):94-101. doi:10.1097/CRD.0b013e3181ceff67.

3. Moscucci MPAGEADBMGCGEARPCSBBAC et al. Grossman \& Baim's Cardiac Catheterization, Angiography, and Intervention. Eight Edition. 8th ed. Philadelphia; 2014

4. PorterTR, SearsT,XieF, etal.Intravascularultrasoundstudy ofangiographically mildly diseased coronary arteries. J Am Coll Cardiol. 1993;22(7):18581865. doi:10.1016/0735-1097(93)90770-2.

5. Fernández AD, Guzzanti D, Lasave L, et al. Consenso de uso de tomografía de coherencia óptica (OCT / OFDI ( Task force consensus in optical coronary tomography. Rev Argentina Cardiol Interv. 2015:1-3.

6. Prati F, Regar E, Mintz GS, et al. Expert review document on methodology, terminology, and clinical applications of optical coherence tomography: Physical principles, methodology of image acquisition, and clinical application for assessment of coronary arteries and atherosclerosis. Eur Heart J. 2010;31(4):401-415. doi:10.1093/eurheartj/ehp433.

7. Gonzalo N, Serruys PW, García-García HM, et al. Comparación cuantitativa ex vivo e in vivo de las dimensiones del lumen medidas por tomografía de coherencia óptica y ecografía intravascular en arterias coronarias humanas. Rev Esp Cardiol. 2009;62(6):615-624. doi:10.1016/503008932(09)71328-4.

8. Prati F, Cera M, Ramazzotti V, Imola F, Giudice R AM. Safety and feasibility of a new non-occlusive technique for facilitated intracoronary optical coherence tomography (OCT) acquisition in various clinical and anatomical scenarios. Eurolntervention. 2007;3(3):365-370.

9. De Bruyne B, Pij/s NHJ, Kalesan B, et al. Fractional flow reserve-guided $P C l$ versus medical therapy in stable coronary disease. N Engl I Med. 2012;367(11):991-1001. doi:10.1056/NEJMoa1205361.

10. William F. Fearon, M.D., Rittenhouse DR, Shortell SM, Fisher ES for the FSI. Fractional Flow Reserve versus Angiography for Guiding Percutaneous Coronary Intervention. NEngl J Med. 2009;360(3):2301-2303. doi:10.1056/NEJMoa0904327.

11. Gonzalo N1, Garcia-Garcia HM, Serruys PW, Commissaris KH, Bezerra H, Gobbens P, Costa M RE. Reproducibility of quantitative optical coherence tomography for stent analysis. Eurolntervention. 2009;5(2):224-232.

12. Gonzalo N, Escaned J, Alfonso F, et al. Morphometric Assessment of Coronary Stenosis Relevance With Optical Coherence Tomography. J Am Coll Cardiol. 2012;59(12):1080-1089. doi:10.1016/j.jacc.2011.09.078.

13. Jang IK, Tearney GJ, MacNeill B, et al. In vivo characterization of coronary atheroscleroticplaquebyuseofopticalcoherencetomography.Circulation. 2005;111(12):1551-1555. doi:10.1161/01.CIR.0000159354.43778.69.In.

14. Liang M, Puri A, Devlin G. The vulnerable plaque: the real villain in acute coronary syndromes. Open Cardiovasc Med J. 2011;5:123-129. doi:10.21 74/1874192401105010123.

15. Kume T, Okura H, Yamada R, et al. Frequency and spatial distribution of thin-cap fibroatheroma assessed by 3-vessel intravascular ultrasound and optical coherence tomography: an ex vivo validation and an initial in vivo feasibilitystudy. Circ J. 2009;73(6):1086-1091. doi:10.1253/circj.CJ-08-0733.
Actualmente, esta información por sí sola no es suficiente para definir con certeza la prevención de SCA. Pero como ya hemos observado, en el marco del SCA, esta herramienta es la única capaz de diferenciar la ruptura de placa con respecto a las otras causas menos frecuentes que originan la trombosis coronaria. Es probable que al ir conociendo de mejor manera la historia natural de esta enfermedad se pueda definir con mayor precisión no solamente placas vulnerables sino quienes son los pacientes más vulnerables para este tipo de eventos, ya que, como demostramos previamente, los métodos de estratificación de riesgo actual no son suficientes, especialmente en predecir eventos en la población joven.
16. KumeT,Akasaka T, Kawamoto T, etal. Measurement of the thickness of the fibrous cap by optical coherence tomography. Am Heart J. 2006;152(4). doi:10.1016/j.ahj.2006.06.030.

17. Tearney GJ, Yabushita H, Houser SL, et al. Quantification of macrophage contentinatheroscleroticplaquesbyopticalcoherencetomography. Circulation. 2003;107(1):113-119. doi:10.1161/01.CIR.0000044384.41037.43.

18. Kume T, Akasaka T, Kawamoto $T$, et al. Assessment of coronary arterial thrombus by optical coherence tomography. Am J Cardiol. 2006;97(12):1713-1717. doi:10.1016/j.amjcard.2006.01.031.

19. Virmani $R$, Burke AP, Farb A, Kolodgie FD. Pathology of the Vulnerable Plaque. J Am Coll Cardiol. 2006;47(8):C13-C18. doi:10.1016/j. jacc.2005.10.065.

20. Alfonso F, Paulo M, Gonzalo N, et al. Diagnosis of spontaneous coronary artery dissection by optical coherence tomography. J Am Coll Cardiol. 2012;59(12):1073-1079. doi:10.1016/j.jacc.2011.08.082.

21. Bezerra HG, Attizzani GF, Sirbu V, Guagliumi G, Costa MA. Optical Coherence Tomography Versus Intravascular Ultrasound to Evaluate Coronary Artery Disease and Percutaneous Coronary Intervention. JCIN. 2013;6(3):228-236. doi:10.1016/j.jcin.2012.09.017.

22. Gauthier DD, Macneill BD, Houser SL, Aretz HT, Halpern EF, Jang I. Evaluation of intracoronary stenting by intravascular optical coherence tomography. Heart. 2003;60(9):317-320.

23. Casella G, Klauss V, Ottani F, Siebert U, Sangiorgio P, Bracchetti D. Impact of intravascular ultrasound-guided stenting on long-term clinical outcome: A meta-analysis of available studies comparing intravascular ultrasound-guided and angiographically guided stenting. Catheter Cardiovasc Interv. 2003;59(3):314-321. doi:10.1002/ccd. 10537.

24. Yoon HJ, Hur SH. Optimization of stent deployment by intravascular ultrasound. Korean J Intern Med. 2012;27(1):30-38. doi:10.3904/ kjim.2012.27.1.30.

25. Hassan AKM, Bergheanu SC, Stijnen T, et al. Late stent malapposition risk is higher after drug-eluting stent compared with bare-metal stent implantation and associates with late stent thrombosis. 2010:1172-1180. doi:10.1093/eurheartj/ehn553.

26. CookS, Wenaweser P, Togni M, et al. Incompletestent apposition and very late stent thrombosis after drug-eluting stent implantation. Circulation. 2007:115(18):2426-2434. doi:10.1161/CIRCULATIONAHA.106.658237.

27. Rodriguez AE1, Rodriguez-Granillo GA PI. Late stent thrombosis: the Damocle's sword of drug eluting stents? Eurolntervention. 2007;4:512-517.

28. Trial H, Guagliumi G, Costa MA, et al. Strut Coverage and Late Malapposition With Paclitaxel-Eluting Stents Compared With Bare Metal Stents in Acute Myocardial Infarction Optical Coherence Tomography Substudy of the Harmonizing Outcomes With Revascularization and Stents in Acute Myocardial Inf. 2011. doi:10.1161/CIRCULATIONAHA.110.963181.

29. Virmani R, Kolodgie FD, Burke AP, Farb A, Schwartz SM. Lessons From Sudden Coronary Death. Aterioscler Thromb Vasc Biol. 2000:1262-1275.

30. Rodriguez-Granillo GA. Detección invasiva de placa vulnerable: Dando vueltas en círculos Invasive detection of vulnerable plaque: Going in circles. Rev Argentina Cardiol Interv. 2012;2:96-101.

31. Takarada S, Imanishi T, Kubo T, et al. Effect of statin therapy on coronary fibrous-cap thickness in patients with acute coronary syndrome: 
Assessment by optical coherence tomography study. 2009;202:491-497. doi:10.1016/j.atherosclerosis.2008.05.014.

32. BruyneB De, Cristea E, Mintz GS, et al. A Prospective Natural-History Study of Coronary Atherosclerosis. N Engl J Med. 2011;(364):226-235.

33. G. Rioufol, MD, PhD; G. Finet, MD, PhD; I. Ginon, MD; X. André-Fouët, MD; R. Rossi ME. Multiple Atherosclerotic Plaque Rupture in Acute Coronary Syndrome A Three-Vessel Intravascular Ultrasound Study. Circulation. 2012;106(7). doi:10.1161/01.CIR.0000025609.13806.31.

34. Sonoda S, Morino Y, Ako J, et al. Impact of final stent dimensions on long-term results following sirolimus-eluting stent implantation: Serial intravascular ultrasound analysis from the SIRIUS trial. J Am Coll Cardiol. 2004;43(11):1959-1963. doi:10.1016/i.jacc.2004.01.044.

35. Ahn JM, Kang SJ, Yoon SH, et al. Meta-analysis of outcomes after intravascular ultrasound-guided versus angiography-guided drug-eluting stent implantation in 26,503 patients enrolled in three randomized trials and 14 observational studies. Am J Cardiol. 2014;113(8):1338-1347. doi:10.1016/j.amjcard.2013.12.043.

36. Witzenbichler B, Maehara A, Weisz G, et al. Relationship between intravascular ultrasound guidance and clinical outcomes after drug-eluting stents: The assessment of dual antiplatelet therapy with drug-eluting stents (ADAPT-DES) study. Circulation. 2014;129(4):463-470. doi:10.1161/ CIRCULATIONAHA.113.003942.

37. Prati F, Guagliumi G, Mintz GS, et al. Expert review document part 2: Methodology, terminology and clinical applications of optical coherence tomography for the assessment of interventional procedures. Eur Heart J. 2012;33(20):2513-2522. doi:10.1093/eurheartj/ehs095.

38. MaeharaA,Ben-YehudaO, AliZ, etal.Comparison ofStentExpansion Guided by Optical Coherence Tomography Versus Intravascular Ultrasound. JACC Cardiovasc Interv. 2015;8(13):1704-1714. doi:10.1016/j.jcin.2015.07.024.

39. Meneveau N, Souteyrand G, Motreff P, et al. Optical Coherence Tomography to Optimize Results of Percutaneous Coronary Intervention in Patients with Non-ST-Elevation Acute Coronary Syndrome: Results of the Multicenter, Randomized DOCTORS (Does Optical Coherence Tomography Optimize Results of Stentin. Circulation. 2016:906-917. doi:10.1161/CIRCULATIONAHA. 116.024393.

40. Sheth TN, Kajander OA, Lavi S, et al. Optical coherence tomography-guided percutaneous coronary intervention in ST-segment-elevation myocardial infarction. Circ Cardiovasc Interv. 2016;9(4). doi:10.1161/CIRCINTERVENTIONS.115.003414.

41. Finn A V., Joner M, Nakazawa G, et al. Pathological correlates of late drug-eluting stent thrombosis: Strut coverage as a marker of endothelialization. Circulation. 2007:115(18):2435-2441. doi:10.1161/CIRCULATIONAHA. 107.693739.

42. Brugaletta S, Heo JH, Garcia-Garcia HM, et al. Endothelial-dependent vaso- motion in a coronary segment treated by ABSORB everolimus-eluting bioresorbable vascular scaffold system is related to plaque composition at the time of bioresorption of the polymer: Indirect finding of vascular reparative therapy? Eur Heart J. 2012;33(11):1325-1333. doi:10.1093/eurheartj/ehr466.

43. Sabaté M, Windecker S, Iñiguez A, et al. Everolimus-eluting bioresorbablestent vs. durable polymer everolimus-eluting metallic stent in patients with ST-segment elevation myocardial infarction: Results of the randomized ABSORBST-segment elevation myocardial infarction-TROFIII trial. Eur Heart J. 2016;37(3):229-240. doi:10.1093/eurheartj/ehv500.

44. Ormiston JA, Serruys PW, Regar E, et al. A bioabsorbable everolimus-eluting coronary stent system for patients with single de-novo coronary artery lesions (ABSORB): a prospective open-label trial. Lancet. 2008;371(9616):899-907. doi:10.1016/50140-6736(08)60415-8.

45. Serruys $P W$, Ormiston JA, Onuma $Y$, et al. A bioabsorbable everolimus-eluting coronary stent system (ABSORB): 2-year outcomes and results from multiple imaging methods. Lancet. 2009;373(9667):897-910. doi:10.1016/S0140-6736(09)60325-1.

46. Serruys PW, Onuma Y, Ormiston JA, et al. Evaluation of the second generation of a bioresorbable everolimus drug-eluting vascular scaffold for treatment of de novo coronary artery stenosis: Six-month clinical and imaging outcomes. Circulation. 2010;122(22):2301-2312. doi:10.1161/CIRCULATIONAHA. 110.970772.

47. Stone GW, Gao R, Kimura T, et al. 1-year outcomes with the Absorb bioresorbable scaffold in patients with coronary artery disease: A patient-level, pooled meta-analysis. Lancet. 2016;387(10025):1277-1289. doi:10.1016/ S0140-6736(15)01039-9.

48. Wykrzykowska JJ, Kraak RP, Hofma SH, et al. Bioresorbable Scaffolds versus Metallic Stents in Routine PCI. AIDA study. N Engl J Med. 2017:NEJMoa1614954. doi:10.1056/NEJMoa1614954.

49. LaRosa JC, Grundy SM, Waters DD, et al. Intensive lipid lowering with atorvastatin in patients with stable coronary disease. N Engl J Med. 2005;352(14):1425-1435. doi:10.1056/NEJMoa050461.

50. Nissen SE. Effect of intensive compared with moderate lipid-lowering therapy on progression of coronary atherosclerosis: a randomized controlled trial. Jama. 2004;291(9):1071-1080. http://dx.doi.org/10.1001/jama.291.9.1071.

51. Bezerra HG, Costa MA, Guagliumi G, Rollins AM, Simon DI. Intracoronary Optical Coherence Tomography: A Comprehensive Review. Clinical and Research Applications. JACC Cardiovasc Interv 2009;2(11):1035-46. doi:10.1016/j.jcin.2009.06.019.

52. Jia H, Abtahian F, Aguirre AD, et al. In vivo diagnosis of plaque erosion and calcified nodule in patients with acute coronary syndrome by intravascularoptical coherence tomography. J Am Coll Cardiol 2013;62(19):1748-58. doi:10.1016/j.jacc.2013.05.071 